\title{
GENDER DIFFERENCES \\ IN CLINICAL MANIFESTATIONS AND COMORBIDITIES IN PATIENTS WITH SLE: A SINGLE-CENTER EXPERIENCE
}

\author{
RAZLIKE MEĐU SPOLOVIMA \\ U KLINIČKIM MANIFESTACIJAMA I KOMORBIDITETIMA \\ OBOLJELIH OD SUSTAVNOG ERITEMSKOG LUPUSA: \\ ISKUSTVA JEDNOG CENTRA
}

\author{
Daniela Marasović Krstulović ${ }^{1}$, Leona Žuvan², Dijana Perkovićc ${ }^{1}$, Dušanka Martinović Kaliterna ${ }^{2}$ \\ ${ }^{1}$ Division of Rheumatology and Clinical Immunology, Department of Internal Medicine, University of Split, \\ School of Medicine, University Hospital Centre Split, Split, Croatia / Zavod za reumatologiju i kliničku imunologiju, \\ Klinika za unutarnje bolesti, Medicinski fakultet Sveučilišta u Splitu, KBC Split, Split, Hrvatska \\ ${ }^{2}$ University of Split, School of Medicine, Split, Croatia / Medicinski fakultet Sveučilišta u Splitu, Split, Hrvatska
}

Corresponding author / Adresa autora za dopisivanje:

Doc. prim dr. sc. Daniela Marasović Krstulović

Department of Rheumatology and Clinical Immunology / Zavod za reumatologiju i kliničku imunologiju

Department of Internal Medicine / Klinika za unutarnje bolesti

University of Split, School of Medicine / Medicinski fakultet Sveučilišta u Splitu

University Hospital Centre Split / Klinički bolnički centar Split

Šoltanska 1,21000 Split

Hrvatska

Tel.: +38521557266

E-mail / e-pošta: daniela.marakrst@gmail.com

Received / Primljeno: March 6, 2020 / 6. ožujka 2020. Accepted / Prihvaćeno: May 31, 2020 / 31. svibnja 2020.

\section{AbSTRACT}

Aim: The aim of this study was to determine gender differences in the clinical manifestations and comorbidities in SLE patients treated at the University Hospital of Split during a ten-year period.

Methods: The medical records of patients diagnosed with SLE were collected from the Outpatient Clinics, ward, and Day Hospital of the Department of Rheumatology and Clinical Immunology of the University Hospital of Split. All SLE manifestations and comorbidities were recorded. The SPSS 25 (IBM, New York, USA) package was used for statistical analysis. Assessment of the differences between the genders was performed by $\chi^{2}$ test, univariate logistic regression, and multivariate logistic regression.

Results: The study included 268 SLE patients, 242 (90\%) females and 26 (10\%) males, aged 22-88 years (median 52; Q1-Q3: 41-62.75 y). In univariate regression analysis significant association was obtained between Sjögren syndrome (SS) and associated neoplasms and the female gender, while antiphospholipid syndrome (APS) and vasculitis were associated with the male gender. In multivariate logistic regression with age and gender as independent variables, a significantly higher frequency of SS $(\mathrm{P}=0.04)$ and associated neoplasms $(\mathrm{P}=0.004)$ were found in females, while vasculitis $(\mathrm{P}=0.014)$ and APS $(\mathrm{P}=0.003)$ were more frequent in males. Significant association was found between younger age and skin changes and lupus nephritis in both genders. In older patients, a significant correlation was found for dyslipidemia, hypertension, osteoporosis, gastritis, and heart involvement.

Conclusion: In our study of SLE patients, SS and associated neoplasms were more common in women, whereas in men vasculitis and APS were more frequent. Lupus nephritis and skin changes occured more frequently in patients of younger age in both genders. In elderly patients, dyslipidemia, hypertension, heart involvement, osteoporosis, and gastritis were more likely to occur. For a better understanding of this problem it is necessary to examine a larger population of patients and monitor it over time.

Keywords: Lupus erythematosus, systemic - diagnosis, epidemiology; Comorbidity; Neoplasms - epidemiology, pathology; Sjogren's syndrome - epidemiology; Vasculitis - epidemiology; Antiphospholipid syndrome - epidemiology; Age distribution; Sex distribution; Logistic models 


\section{SAŽETAK}

Cilj: Cilj je ovog istraživanja bio ispitati razlike u kliničkim manifestacijama i komorbiditetima između muškaraca i žena oboljelih od SLE-a i liječenih u KBC-u Split.

Ispitanici i metode: Podatci bolesnika koji su imali dijagnozu SLE-a u razdoblju od 1. 1. 2007. godine do 31. 12. 2016. prikupljeni su iz ambulanta, stacionara i dnevne bolnice Zavoda za reumatologiju i kliničku imunologiju Klinike za unutarnje bolesti Kliničkoga bolničkog centra Split. Analizirani su sve zabilježene kliničke manifestacije i pridruženi komorbiditeti. Za statističku je analizu upotrijebljen paket SPSS 25 (IBM, New York, SAD). Služili smo se $\chi^{2}$-testom te univarijatnom i multivarijatnom logističkom regresijom.

Rezultati: Istraživanje je obuhvatilo 268 bolesnika s dijagnozom SLE-a: 26 muškaraca (10\%) i 242 žene (90\%). Medijan dobi ispitanika iznosio je 52 godine (min. - maks.: 22 - 88 god.; Q1 - Q3: 41 - 62,75 god.). $\chi^{2}$-testom utvrdili smo da je ženski spol bio znatno povezan sa Sjögrenovim sindromom (SS) i pridruženim neoplazmama, a antifosfolipidni sindrom (APS) i vaskulitis bili su povezani s muškim spolom. S obzirom na medijan dobi svoje smo ispitanike podijelili u tri skupine. Multivarijatnom logističkom regresijom u kojoj su neovisne varijable bile dob i spol dobili smo statistički značajnu povezanost SS-a $(P=0,04)$ i pridruženih neoplazma $(P=0,004)$ sa ženskim spolom, dok su u muškaraca učestaliji bili vaskulitis $(\mathrm{P}=0,014)$ i APS $(\mathrm{P}=0,03)$.

Zaključak: Prema našem istraživanju bolesnika sa SLE-om, u žena su bili učestaliji SS i pridružene neoplazme, a u muškaraca vaskulitis i APS. Lupus nefritis i kožne promjene češće se javljaju u bolesnika mlađe dobi u oba spola. Kod starijih su bolesnika češći dislipidemija, hipertenzija, zahvaćenost srca, osteoporoza i gastritis. Radi jasnijeg objašnjenja ovog problema potrebno je istražiti puno veću populaciju bolesnika te ih pratiti dulje razdoblje.

KLJUČNE RIJEČI: Sistemski eritemski lupus - dijagnoza, epidemiologija; Komorbiditet; Tumori - epidemiologija, patologija; Sjögrenov sindrom - epidemiologija; Vaskulitis - epidemiologija; Antifosfolipidni sindrom - epidemiologija; Dobna distribucija; Spolna distribucija; Logistički modeli

\section{INTRODUCTION}

Systemic lupus erythematosus (SLE) is a chronic inflammatory autoimmune disease of unknown etiology that affects numerous organs and organ systems. A feature of the disease is chronic inflammation characterized by the formation of autoantibodies and immune complexes that damage tissues and cells. The clinical picture is characterized by alternating exacerbations and remissions, and the course and prognosis of the disease are unpredictable (1). As many as $90 \%$ of patients are women, predominantly of reproductive age, which is attributed to the effect of estrogen on the development of SLE, but the disease can also occur in children and the elderly, when the difference in gender distribution is much smaller (2).

The clinical manifestations of SLE are diverse, often nonspecific, and can be confused with some other diseases. It takes an average of five years to diagnose the disease, which worsens its prognosis. Survival of patients with SLE has improved significantly in the last fifty years, accompanied by an increasing number of comorbidities (3). A large study of 7,732 subjects with SLE showed that the incidence of cardiovascular disease (CVD), stroke, end-stage renal disease, cancer, osteoporosis, and infection was 1.28-7.81 times higher in patients (4).

CVD is the main comorbidity and cause of earlier mortality in SLE, and occurs 3-4 times more often and earlier in these patients than in the general population. The CV risk is higher in younger patients. According to the multinational SLICC cohort, 50/97 vascular

\section{UVOD}

Sustavni eritemski lupus (SLE) kronična je upalna autoimunosna bolest nepoznate etiologije koja zahvaća brojne organe i organske sustave. Obilježje bolesti jest kronična upala karakterizirana stvaranjem autoprotutijela i imunokompleksa koji oštećuju tkiva i stanice. Kliničku sliku obilježavaju naizmjenične egzacerbacije i remisije, a tijek i prognoza bolesti nepredvidivi su (1). Čak $90 \%$ oboljelih jesu žene, i to dominantno one reproduktivne dobi, što se pripisuje utjecaju estrogena na razvoj SLE-a, no bolest se može pojaviti i kod djece i starijih ljudi kada je razlika u spolnoj distribuciji znatno manja (2).

Klinička očitovanja SLE-a raznolika su, često nespecifična i mogu se zamijeniti s nekim drugim bolestima. Do dijagnosticiranja bolesti u prosjeku prođe pet godina, što pogoršava njezinu prognozu. Posljednjih pedeset godina znatno se poboljšalo preživljenje bolesnika sa SLE-om, što prati sve veći broj komorbiditeta (3). Veliko istraživanje na 7732 ispitanika sa SLE-om pokazalo je da je incidencija kardiovaskularnih bolesti (KVB), moždanog udara, terminalnog stadija bubrežne bolesti, karcinoma, osteoporoze i infekcija 1,28 7,81 puta veća u oboljelih (4).

KVB je glavni komorbiditet i uzrok ranije smrtnosti pri SLE-u, a javlja se 3 - 4 puta učestalije i prije u ovih bolesnika nego u općoj populaciji. KV rizik najviši je kod mlađih bolesnika. Prema multinacionalnoj kohorti SLICC, 50/97 vaskularnih događaja bilo je posljedica aktivnog lupusa, 31 ateroskleroze i 16 nekoga drugog uzroka, što upućuje na njihovo multifaktorsko 
events were due to active lupus, 31 to atherosclerosis, and 16 to some other cause, suggesting their multifactorial origin in patients with SLE (5). Malignant tumors considered to be more common in people with SLE are: hematological tumors, lung tumors, cervical cancer and dysplasia, and head and neck tumors.

Tumors that have a lower prevalence among SLE patients than among the general population are breast, endometrial, and prostate tumors. Among hematological malignancies there is an increased incidence of and mortality from non-Hodgkin lymphoma and an increased risk of Hodgkin lymphoma, leukemia, and multiple myeloma. Dysplasia and cervical cancer occur as a result of the increased prevalence of HPV infection among patients with SLE. A possible explanation for this infection is inadequate removal of the virus caused by a genetic immune disorder, impaired innate immunity, or the action of immunosuppressants (6).

Other autoimmune diseases such as endocrine autoimmune diseases (Hashimoto thyroiditis, autoimmune hepatitis, type I diabetes) and antiphospholipid syndrome (APS) are often associated with SLE. Systemic infections (most commonly pneumonia and sepsis) are one of the three most common causes of morbidity and mortality in patients with SLE along with active SLE and thrombosis, and are the second most common cause of hospitalization in patients with SLE after an exacerbation of the underlying disease (8).

Numerous studies have shown differences between the genders in the clinical manifestations and comorbidities of SLE. A 2016 meta-analysis (16 studies, 11,934 patients) suggested that alopecia, photosensitivity, butterfly rash, oral ulcers, and arthritis are significantly more common in women, while lupus nephritis, serositis, and thrombocytopenia are more common in men (9).

The aim of this study was to determine differences in the clinical picture and comorbidities between the genders in SLE patients treated in the University Hospital of Split between 2007 and 2017.

\section{MATERIALS AND METHODS}

This is a cross-sectional, retrospective study using data collected from the medical history of patients treated at the Department of Rheumatology and Clinical Immunology, as well as the medical history and electronic data of patients treated at the Day Hospital of the Department and electronic data from the two Rheumatology Clinics of the Department of Internal Medicine, Clinical Hospital Center Split in the period from January 1, 2007 to December 31, 2016. Inclusion criteria were: a diagnosis of SLE according to the 1984 American Rheumatological Society (ACR) critera and age over 18 years. podrijetlo u bolesnika sa SLE-om (5). Maligni tumori za koje se smatra da su češći u oboljelih od SLE-a jesu: hematološki tumori, tumori pluća, rak i displazije vrata maternice te tumori glave i vrata. Tumori koji imaju manju prevalenciju među oboljelima od SLE-a nego među općom populacijom jesu tumori dojke, endometrija i prostate. Od hematoloških maligniteta povećane su incidencija i smrtnost od ne-Hodgkinova limfoma te je povišen rizik od Hodgkinova limfoma, leukemije i multiplog mijeloma. Displazije i rak vrata maternice nastaju kao posljedica povećane prevalencije infekcije HPV-om među bolesnicama sa SLE-om. Moguće objašnjenje ove infekcije jest neadekvatno uklanjanje virusa uzrokovano genskim imunosnim poremećajem, poremećenom prirođenom imunosti ili djelovanjem imunosupresiva (6).

Često su SLE-u pridružene i druge autoimunosne bolesti poput endokrinih autoimunosnih bolesti (Hashimotov tiroiditis, autoimunosni hepatitis, šećerna bolest tipa I) i antifosfolipidni sindrom (APS) (7). Sustavne infekcije (najčešće pneumonije i sepse) jedan su od tri najčešća uzroka morbiditeta i mortaliteta u bolesnika sa SLE-om, uz aktivan SLE i tromboze, te su drugi uzrok hospitalizacija bolesnika sa SLE-om, odmah nakon pogoršanja osnovne bolesti (8).

Brojna istraživanja pokazuju razlike u kliničkim manifestacijama i komorbiditetima između spolova. Metaanaliza iz 2016. godine (16 istraživanja, 11.934 bolesnika) upućuje na to da su alopecija, fotosenzitivnost, leptirasti osip, oralni ulkusi i artritis znatno češći u žena, dok su lupus nefritis, serozitis i trombocitopenija učestaliji u muškaraca (9).

Cilj je ovog istraživanja bio ispitati postoje li razlike u kliničkoj slici i komorbiditetima među spolovima kod oboljelih od SLE-a u populaciji bolesnika liječenih u KBC-u Split od 2007. do 2017. godine.

\section{MATERIJALI I METODE}

Ovo je presječno, retrospektivno istraživanje, a kao izvor podataka upotrijebljeni su podatci prikupljeni iz povijesti bolesti bolesnika liječenih u stacionaru Zavoda za reumatologiju i kliničku imunologiju, zatim povijesti bolesti i elektronički podatci bolesnika liječenih u Dnevnoj bolnici Zavoda te elektronički podatci iz dviju reumatoloških ambulanta Zavoda Klinike za unutarnje bolesti KBC-a Split, u razdoblju od 1. siječnja 2007. do 31. prosinca 2016. Kao kriterije uključenja uzeli smo dijagnosticiran SLE i dob višu od 18 godina. Dijagnoza SLE-a nalagala je ispunjenje kriterija Američkoga reumatološkog društva (ACR) iz 1984. godine. Iz povijesti bolesti prikupili smo podatke o dobi, spolu te kliničkim manifestacijama i komorbiditetima. Od kliničkih manifestacija u obzir smo uzeli: kožne promjene, zahvaćenost srca, lupus nefritis, depresiju, za- 
Data on age, gender, and clinical manifestations and comorbidities were collected from the disease history. The following clinical manifestations were taken into account: skin changes, heart involvement, lupus nephritis, depression, CNS involvement, joint involvement, APS (revised Sappor criteria from 2006), anemia, thrombocytopenia, pleuritis, psychosis, osteonecrosis, and vasculitis. Recorded comorbidities were: osteoporosis, osteopenia, SS, diabetes, chronic thyroiditis, hypertension, dyslipidemia, systemic infections, rheumatoid arthritis, gastritis, and associated neoplasms. The variable heart involvement included: diseases of the endocardium, myocardium, pericardi$\mathrm{um}$, and coronary blood vessels. In systemic infections we analyzed all those that required hospitalization of the patients. Regarding the associated neoplasms, both benign and malignant neoplasms were included. We included all types of vasculitis, except for CNS vasculitis, which was considered as CNS involvement. The diagnosis of vasculitis was based on clinical, histological, or radiological diagnostics. Skin changes included butterfly rash, discoid rash, photosensitivity, oral ulceration, alopecia, and Raynaud phenomenon. The Ethics Committee of the University Hospital of Split approved the implementation of this research.

\section{Statistical analysis}

The collected data were entered into a computer database using the SPSS 25 for Windows program (IBM, New York, USA). We used $\chi 2$-test, univariate logistic regression, and multivariate logistic regression. A P-value lower than 0.05 was taken as statistically significant. Data are presented as absolute values, percentages, and odds ratio (OR).

\section{RESULTS}

The study included 268 patients with SLE, who were $\geq$ 18 years of age at the time of inclusion. The median age of the respondents was 52 years ( $22-88$ years). The respondents were divided into 3 groups according to age: $\leq 50$ years, $50-70$ years, and $\geq 70$ years. Of the total number of respondents, $26(10 \%)$ were men and 242 (90\%) women. Table 1 shows the number (\%) of patients by age groups, type of clinical manifestations, and comorbidities that did not differ according to gender.

Table 2 shows the number (\%) of patients by type of clinical manifestations and comorbidities with a significant difference between the genders. Since there were no males older than 70 years, we analyzed the clinical manifestations and comorbidities in relation to two age groups ( $\leq 50$ and $50-70$ ), because those two age groups were gender-aligned. Table 3 shows the number (\%) of patients according to the type of clinical manifestations and comorbidities that differed be- hvaćenost SŽS-a, zahvaćenost zglobova, APS (revidirani kriteriji iz Sappora iz 2006. godine), anemiju, trombocitopeniju, pleuritis, psihozu, osteonekrozu, vaskulitis. Od komorbiditeta zabilježili smo: osteoporozu, osteopeniju, SS, šećernu bolest, kronični tiroiditis, hipertenziju, dislipidemiju, sustavne infekcije, reumatoidni artritis, gastritis, pridružene neoplazme. U varijablu zahvaćenost srca uključili smo: bolesti endokarda, miokarda i perikarda te koronarnih krvnih žila. U sustavne smo infekcije uključili sve one koje su iziskivale hospitalizaciju bolesnika. U pridružene neoplazme uključili smo i benigne i maligne neoplazme. U vaskulitis smo uključili sve vrste vaskulitisa, osim vaskulitisa SŽS-a koji smo računali kao zahvaćenost SŽS-a. Dijagnoza vaskulitisa bila je postavljena na temelju kliničke, histološke ili radiološke dijagnostike. U kožne smo promjene uvrstili leptirasti osip, diskoidni osip, fotosenzitivnost, oralne ulceracije, alopeciju i Raynaudov fenomen.

Etičko povjerenstvo KBC-a Split odobrilo je provođenje ovog istraživanja.

\section{Statistička obrada}

Prikupljeni podatci uneseni su u računalnu bazu podataka pri čemu smo rabili program SPSS 25 for Windows (IBM, New York, SAD). Služili smo se $\chi^{2}$-testom, univarijatnom logističkom regresijom i multivarijatnom logističkom regresijom. P-vrijednost niža od 0,05 uzeta je kao statistički značajna. Podatci su prikazani kao apsolutne vrijednosti, postotci i OR (engl. odds ratio).

\section{REZULTATI}

Istraživanjem je obuhvaćeno 268 bolesnika sa SLE-om, koji su u trenutku uključivanja imali $\geq 18$ godina. Medijan dobi ispitanika iznosio je 52 godine (min. - maks.: 22 - 88 godina). Ispitanike smo, prema dobi, podijelili u 3 skupine: $\leq 50$ godina, $50-70$ godina, $\geq 70$ godina. Od ukupnog broja ispitanika bilo je 26 muškaraca (10\%) i 242 žene (90\%). Na tablici 1. prikazan je broj (\%) bolesnika prema dobnim skupinama, vrsti kliničkih manifestacija i komorbiditetima koji se nisu razlikovali s obzirom na spol. Na tablici 2. prikazan je broj (\%) bolesnika prema vrsti kliničkih manifestacija i komorbiditetima sa zabilježenom znatnom razlikom među spolovima. Nijedan muškarac nije bio stariji od 70 godina pa smo analizu kliničkih manifestacija i komorbiditeta napravili u odnosu prema dvjema dobnim skupinama $(\leq 50,50-70)$, jer su te dvije dobne skupine bile usklađene prema spolovima. $\mathrm{Na}$ tablici 3. prikazan je broj (\%) bolesnika prema vrsti kliničkih manifestacija i komorbiditetima koji su se razlikovali među spolovima ukupno i u odnosu prema dobnim skupinama ( $\leq 50$ i 50 - 70 godina). Sumarni 
TABLE 1. Distribution of patients by age groups, type of clinical manifestations, and comorbidities that did not differ between the genders

TABLICA 1. Raspodjela bolesnika prema dobnim skupinama, vrsti kliničkih manifestacija i komorbiditetima koji se nisu razlikovali prema spolovima

\begin{tabular}{|c|c|c|c|c|c|}
\hline & & \multirow{2}{*}{$\begin{array}{l}\text { Total / Ukupno } \\
\quad(\mathrm{n}=268)\end{array}$} & \multicolumn{2}{|c|}{ Gender / Spol } & \multirow{2}{*}{$P^{*}$} \\
\hline & & & $\begin{array}{l}\text { Men / muškarci } \\
\quad(\mathrm{n}=26)\end{array}$ & $\begin{array}{l}\text { Women / žene } \\
\quad(\mathrm{n}=242)\end{array}$ & \\
\hline \multirow{3}{*}{$\begin{array}{l}\text { Age groups (years) } \\
\text { / Dobne skupine (god.) }\end{array}$} & $<50$ & $116(43)$ & $14(54)$ & $102(42)$ & 0,189 \\
\hline & $50-70$ & $128(48)$ & $12(46)$ & $116(48)$ & \\
\hline & $>70$ & $24(9)$ & 0 & $24(10)$ & \\
\hline Skin changes / Kožne promjene & $\mathrm{da}$ & $112(42)$ & $14(54)$ & $98(40)$ & 0,270 \\
\hline Heart disorders / Srčane tegobe & da & $38(14)$ & $3(11)$ & $35(14)$ & 0,906 \\
\hline Kidneys / Bubrezi & $\mathrm{da}$ & $64(24)$ & $8(31)$ & $56(23)$ & 0,532 \\
\hline Osteoporosis / Osteoporoza & $\mathrm{da}$ & $42(16)$ & $1(4)$ & $41(17)$ & 0,144 \\
\hline Depression / Depresija & $\mathrm{da}$ & $36(13)$ & $1(4)$ & $35(14)$ & 0,228 \\
\hline CNS / SŽS & da & $30(11)$ & $3(11)$ & $27(11)$ & 1 \\
\hline Joints / Zglobovi & $\mathrm{da}$ & $78(29)$ & $11(42)$ & $67(28)$ & 0,183 \\
\hline Diabetes / Šećerna bolest & $\mathrm{da}$ & $17(6,4)$ & $1(4)$ & $16(7)$ & 0,895 \\
\hline Chronic thyroiditis / Kronični tiroiditis & $\mathrm{da}$ & $41(15)$ & $1(4)$ & $40(16)$ & 0,155 \\
\hline Sustavna infekcija / Systemic infection & da & $58(22)$ & $9(35)$ & $49(20)$ & 0,153 \\
\hline RA & da & $35(13)$ & $3(11)$ & $32(13)$ & 1 \\
\hline Thrombocytopenia / Trombocitopenija & $\mathrm{da}$ & $43(16)$ & $4(15)$ & $39(16)$ & 1 \\
\hline Anemia / Anemija & da & $136(51)$ & $14(54)$ & $122(51)$ & 0,916 \\
\hline Gastritis / Gastritis & $\mathrm{da}$ & $43(16)$ & $3(11)$ & $40(16)$ & 0,706 \\
\hline Osteopenia / Osteopenija & $\mathrm{da}$ & $20(7)$ & $2(8)$ & $18(7)$ & 1 \\
\hline
\end{tabular}

$P<0,05 ;$ CNS / SŽS = central nervous system / središnji živčani sustav; $R A=$ rheumatoid arthritis / reumatoidni artritis

TABLE 2. Distribution of patients with SLE according to the type of comorbidity that differed between the genders TABLICA 2. Raspodjela bolesnika sa SLE-om prema vrsti komorbiditeta koji su se razlikovali medu spolovima

\begin{tabular}{|c|c|c|c|c|c|c|c|}
\hline & & \multirow{2}{*}{$\begin{array}{l}\text { Total / Ukupno } \\
\quad(\mathrm{n}=268)\end{array}$} & \multicolumn{2}{|c|}{ Gender / Spol } & \multirow[b]{2}{*}{$P^{*}$} & \multirow[b]{2}{*}{ OR (95\%-tni CI) } & \multirow[b]{2}{*}{$P^{* *}$} \\
\hline & & & $\begin{array}{l}\text { Men / muškarci } \\
\quad(\mathrm{n}=26)\end{array}$ & $\begin{array}{l}\text { Women / žene } \\
\quad(\mathrm{n}=242)\end{array}$ & & & \\
\hline $\begin{array}{l}\text { Sjögren syndrome } \\
\text { / Sjögrenov sindrom }\end{array}$ & $\mathrm{da}$ & $60(23)$ & $1(4)$ & $59(25)$ & 0,031 & $8(1,1-61)$ & 0,042 \\
\hline APS & da & $45(17)$ & $10(38)$ & $35(15)$ & 0,005 & $3,7(1,5-8,7)$ & 0,003 \\
\hline Hypertension / Hipertenzija & $\mathrm{da}$ & $93(35)$ & $4(15)$ & $89(37)$ & 0,05 & $3,2(1,1-9,5)$ & 0,038 \\
\hline Dyslipidemia / Dislipidemija & $\mathrm{da}$ & $120(45)$ & $6(23)$ & $114(47)$ & 0,033 & $2,9(1,1-7,6)$ & 0,024 \\
\hline Neoplasia / Neoplazija & $\mathrm{da}$ & $66(25)$ & $1(4)$ & $65(27)$ & 0,019 & $9,2(1,2-69)$ & 0,031 \\
\hline Vasculitis / Vaskulitis & da & $17(6)$ & $5(19)$ & $12(5)$ & 0,016 & $4,5(1,4-14)$ & 0,009 \\
\hline
\end{tabular}

$P<0,05 ; A P S=$ antiphospholipid syndrome / antifosfolipidni sindrom

tween the genders in total and in relation to the age groups ( $\leq 50$ and $50-70$ years).

The summary results of univariate logistic regression with gender and age groups as independent variables are shown in Table 4. Multivariate logistic regression, in which the independent variables were gender and age group, found that the following variables were age group-related: skin changes, heart, kidney, hypertension, dyslipidemia, osteoporosis, anemia, and gas- rezultati univarijatne logističke regresije sa spolom i dobnim skupinama kao neovisnim varijablama prikazani su na tablici 4. Multivarijatnom logističkom regresijom, u kojoj su nezavisne varijable bili spol i dobne skupine, dobili smo da su samo za dobnu skupinu vezane ove varijable: kožne promjene, srce, bubrezi, hipertenzija, dislipidemija, osteoporoza, anemija i gastritis. Multivarijantnom logističkom regresijom, u kojoj smo kao zavisnu varijablu uzeli svaku od kliničkih ma- 
TABLE 3. Distribution of patients according to the type of clinical manifestations and comorbidities that differed between the genders in total and in relation to age groups ( $<50$ and $50-70$ years)

TABLICA 3. Raspodjela bolesnika prema vrsti kliničkih manifestacija i komorbiditetima koji su se razlikovali medu spolovima ukupno i s obzirom na dobne skupine (< 50 i 50 - 70 godina)

\begin{tabular}{|c|c|c|c|c|c|c|c|}
\hline & & \multirow{2}{*}{$\begin{array}{l}\text { Total / Ukupno } \\
\quad(\mathrm{n}=244)\end{array}$} & \multicolumn{2}{|c|}{ Age (years) / Dob (godina) } & \multirow[b]{2}{*}{$P^{*}$} & \multirow[b]{2}{*}{ OR (95\%-tni CI) } & \multirow[b]{2}{*}{$P^{*}$} \\
\hline & & & $\begin{array}{c}<50 \\
(n=116)\end{array}$ & $\begin{array}{c}50-70 \\
(\mathrm{n}=128)\end{array}$ & & & \\
\hline Skin changes / Kožne promjene & yes / da & $104(43)$ & $58(50)$ & $46(36)$ & 0,037 & $1,8(1,1-3)$ & 0,027 \\
\hline Heart disorders / Srčane tegobe & yes / da & $35(14)$ & $10(9)$ & $25(20)$ & 0,023 & $2,6(1,2-5,7)$ & 0,017 \\
\hline Kidneys / Bubrezi & yes / da & $61(25)$ & $38(33)$ & $23(18)$ & 0,012 & $2,2(1,2-4)$ & 0,008 \\
\hline Osteoporosis / Osteoporoza & yes / da & $33(13)$ & $5(4)$ & $28(22)$ & $<0,001$ & $6,2(2,3-17)$ & $<0,001$ \\
\hline Hypertension / Hipertenzija & yes / da & $80(32)$ & $24(21)$ & $56(44)$ & $<0,001$ & $3(1,7-5,3)$ & $<0,001$ \\
\hline Dyslipidemia / Dislipidemije & yes / da & $102(42)$ & $35(30)$ & $67(52)$ & 0,001 & $2,5(1,5-4,3)$ & 0,001 \\
\hline Gastritis / Gastritis & yes / da & $38(16)$ & $10(9)$ & $28(22)$ & 0,007 & $3(1,4-6,4)$ & 0,006 \\
\hline
\end{tabular}

${ }^{*} P<0,05$

TABLE 4. Summary table of univariable logistic regression $(95 \% \mathrm{CI})$ of covariables that demonstrated a statistically significant association with gender or age groups $(\mathrm{P}<0.05)$

TABLICA 4. Sumarna tablica univarijatne logističke regresije. OR (95\%-tni CI) onih kovarijabla koje su pokazale statistički značajnu povezanost sa spolom ili dobnim skupinama $(P<0,05)$

\begin{tabular}{|c|c|c|c|c|}
\hline & Gender / Spol & $\begin{array}{c}\text { Reference level } \\
\text { for gender } \\
\text { / Referentna razina } \\
\text { za spol }\end{array}$ & $\begin{array}{l}\text { Age groups } \\
\text { / Dobne skupine }\end{array}$ & $\begin{array}{l}\text { Reference level } \\
\text { for age } \\
\text { / Referentna razina } \\
\text { za dob }\end{array}$ \\
\hline Skin changes / Kožne promjene & & & $1,8(1,1-3)$ & $50-70$ godina \\
\hline Heart disorders / Srčane tegobe & & & $2,6(1,2-5,7)$ & $<50$ godina \\
\hline Lupus nephritis / Lupusni nefritis & & & $2,2(1,2-4)$ & $50-70$ godina \\
\hline Osteoporosis / Osteoporoza & & & $6,2(2,3-17)$ & $<50$ godina \\
\hline Hypertension / Hipertenzija & $3,2(1,1-9,5)$ & men / muškarci & $3(1,7-5,3)$ & $<50$ godina \\
\hline Dyslipidemia / Dislipidemija & $2,9(1,1-7,6)$ & men / muškarci & $2,5(1,5-4,3)$ & $<50$ godina \\
\hline Gastritis & & & $3(1,4-6,4)$ & $<50$ godina \\
\hline Sjögren syndrome / Sjögrenov sindrom & $8(1,1-61)$ & men / muškarci & & \\
\hline APS & $3,7(1,5-8,7)$ & woman / žene & & \\
\hline Associated neoplasms / Pridružene neoplazme & $9,2(1,2-69)$ & men / muškarci & & \\
\hline Vasculitis / Vaskulitis & $4,5(1,4-14)$ & woman / žene & & \\
\hline
\end{tabular}

$\chi^{2}$-test; logistic regression / logistička regresija

tritis. Multivariate logistic regression, in which the dependent variables were the clinical manifestations and comorbidities whose gender difference was significant in univariate analysis, and the independent variables were gender and age group, confirmed the association of SS, APS, associated neoplasms, and vasculitis with gender (Table 5, Figures 1 to 4).

\section{DISCUSSION}

The main results of our study suggest the existence of significant differences in the incidence of certain clinical manifestations and comorbidities between men and women with SLE in our population. A higher incidence of APS and vasculitis was found in men, and nifestacija i komorbiditete čija je razlika među spolovima bila znatna u univarijatnoj analizi, a kao nezavisne varijable spol i dobne skupine, potvrdili smo povezanost SS-a, APS-a, pridruženih neoplazma i vaskulitisa sa spolom (tablica 5., slike 1. do 4.).

\section{RASPRAVA}

Glavni rezultati našeg istraživanja upućuju na postojanje znatnih razlika u pojavnosti pojedinih kliničkih manifestacija i komorbiditeta između muškaraca i žena oboljelih od SLE-a u našoj populaciji. U muškaraca je utvrđena veća pojavnost APS-a i vaskulitisa, a u žena pridruženih neoplazma i SS-a. U muškaraca je 2,5 puta veći udio bolesnika imao APS, dok je izgled za 
TABLE 5. Results of multivariate logistic regression for comorbidities that demonstrated a difference between the genders in univariate logistic regression TABLICA 5. Rezultati multivarijatne logističke regresije za komorbiditete koji su u univarijatnoj logističkoj regresiji pokazivali razliku među spolovima

\begin{tabular}{|c|c|c|c|}
\hline $\begin{array}{l}\text { Dependent } \\
\text { variable } \\
\text { / Zavisna } \\
\text { varijabla }\end{array}$ & $\begin{array}{l}\text { Independent } \\
\text { variables } \\
\text { / Nezavisne } \\
\text { varijable }\end{array}$ & $\begin{array}{c}\text { OR } \\
(95 \% \text {-tni CI })\end{array}$ & $P^{\star *}$ \\
\hline \multirow{2}{*}{$\begin{array}{l}\text { Sjögren } \\
\text { syndrome } \\
\text { / Sjögrenov } \\
\text { sindrom }\end{array}$} & $\begin{array}{l}\text { Gender }\left(\text { men }^{*}\right) \\
\text { / Spol }(\text { muškarci }\end{array}$ & $8,4(1,1-63)$ & 0,04 \\
\hline & Age / Dob & $1,7(0,92-3)$ & 0,09 \\
\hline \multirow[t]{2}{*}{ APS } & $\begin{array}{c}\text { Gender }\left(\text { women }^{*}\right) \\
\text { / Spol }\left(\text { žene }{ }^{\star}\right)\end{array}$ & $3,8(1,6-9,2)$ & 0,003 \\
\hline & Age / Dob & $0,72(0,36-1,5)$ & 0,363 \\
\hline \multirow{2}{*}{$\begin{array}{l}\text { Associated } \\
\text { neoplasms } \\
\text { / Pridružene } \\
\text { neoplazme }\end{array}$} & $\begin{array}{l}\text { Gender }\left(\text { men }^{*}\right) \\
\text { / Spol }\left(\text { muškarci }{ }^{\star}\right)\end{array}$ & $8,5(1,1-64)$ & 0,039 \\
\hline & Age / Dob & $1,6(0,5-2,9)$ & 0,147 \\
\hline \multirow[t]{2}{*}{$\begin{array}{l}\text { Vasculitis } \\
\text { / Vaskulitis }\end{array}$} & $\begin{array}{l}\text { Gender }\left(\text { women }{ }^{\star}\right) \\
\text { / Spol }\left(\text { žene }{ }^{\star}\right)\end{array}$ & $4,2(1,3-13)$ & 0,014 \\
\hline & Age / Dob & $1,4(0,51-3,9)$ & 0,515 \\
\hline
\end{tabular}

Data are shown as OR (95\% CI)

/ Podatci su prikazani kao OR (95\%-tni CI)

* reference level / referentna razina;

** logistic regression / logistička regresija

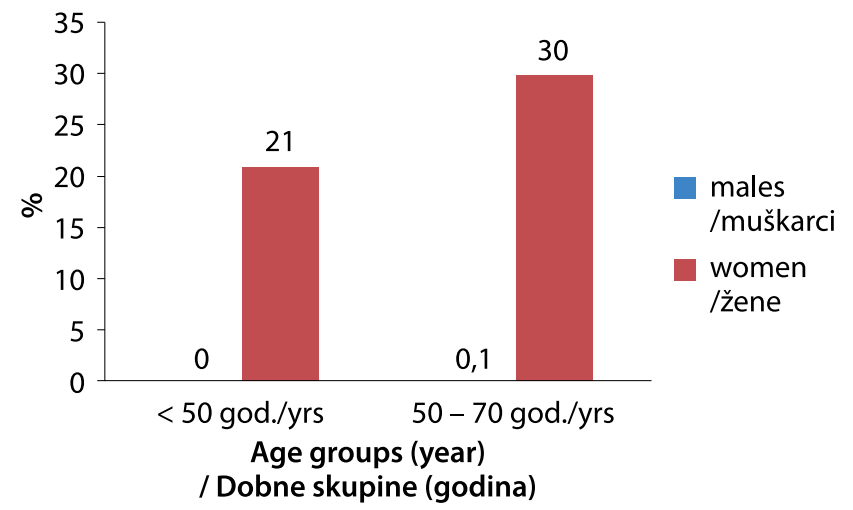

Age < 50 y / Dob < 50 g.: N men / N muškaraca = 14; $N$ women / N žena = 10; Age / Dob 50-70 y / godina: $N$ men $/ N$ muškaraca $=12, N$ women $/ N$ žena $=116$

FIgURE 1. Proportion of Sjögren syndrome (\%) by gender and age groups

SLIKA 1. Udio Sjögrenova sindroma (\%) prema spolu i dobnim skupinama

in women there was higher incidence of associated neoplasms and SS. In men there was a 2.5 times higher proportion of patients with APS, while the incidence of APS was 3.7 times higher than in women. These results coincide with the results of several published studies. In almost all studies which showed a difference in the incidence of APS between men and women with SLE, APS was more common in men $(10-13)$.

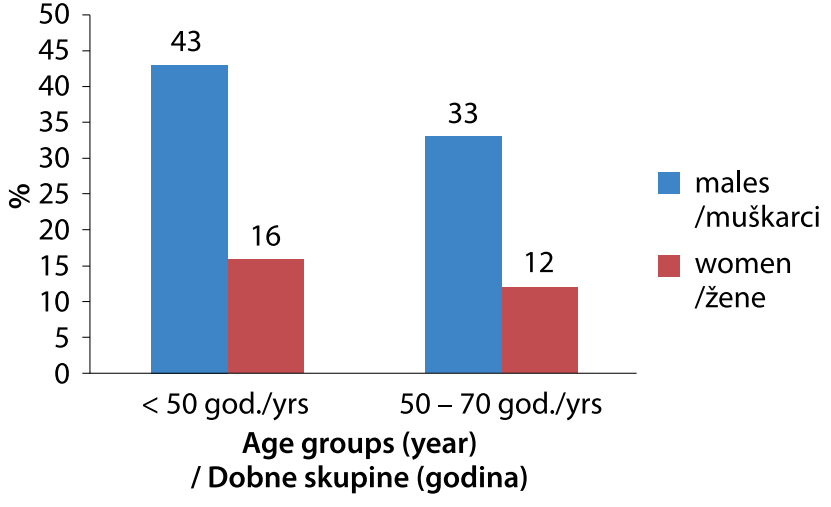

Age $<50$ y / Dob $<50$ g.: N men / N muškaraca = 14;

N women / N žena = 102; Age / Dob $50-70$ y / godina:

$N$ men / $N$ muškaraca $=12, N$ women $/ N$ žena $=116$

Figure 2. Proportion of APS (\%) by gender and age groups

SLIKA 2. Udio APS-a (\%) prema spolu i dobnim skupinama

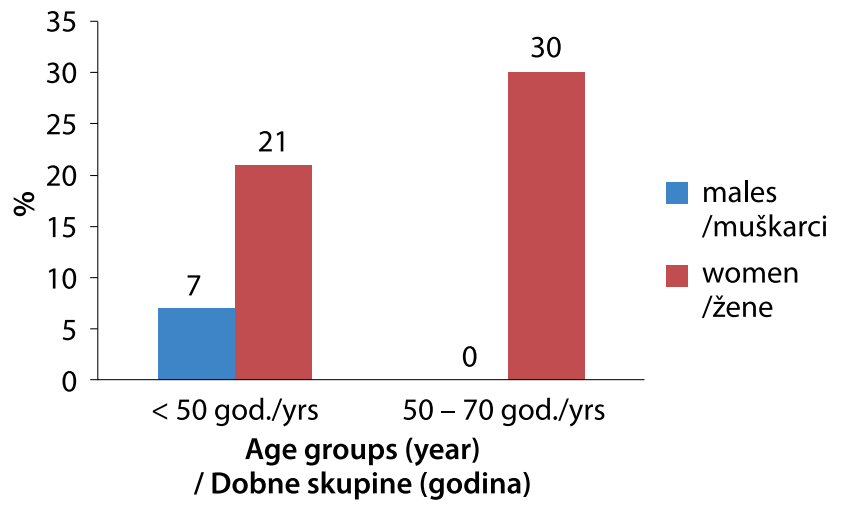

Age $<50$ y / Dob < 50 g.: N men / N muškaraca = 14; $N$ women / N žena = 102; Age / Dob $50-70$ y / godina: $N$ men $/ N$ muškaraca $=12, N$ women $/ N$ žena $=116$

Figure 3. Proportion of neoplasms (\%) by gender and age groups

SLIKA 3. Udio pridruženih neoplazma (\%) prema spolu i dobnim skupinama

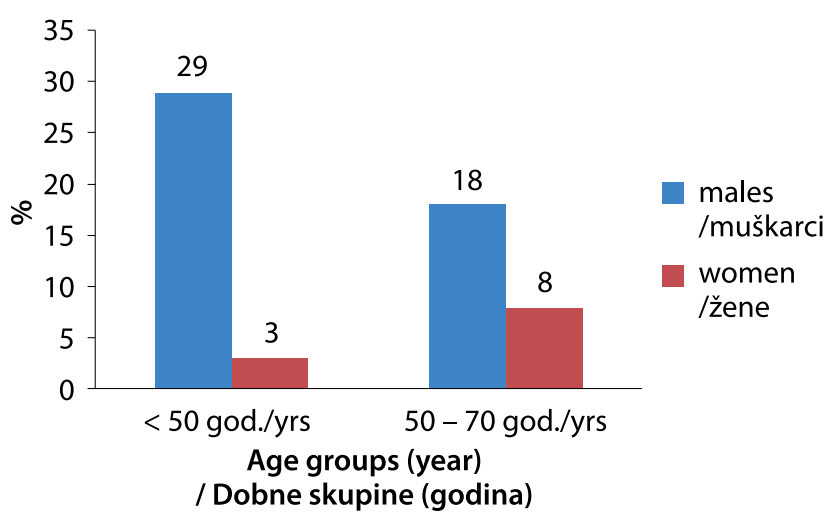

Age $<50$ y / Dob $<50$ g.: N men / N muškaraca = 14; $N$ women / N žena = 102; Age / Dob $50-70$ y / godina: $N$ men $/ N$ muškaraca $=12, N$ women $/ N$ žena $=116$

FIGURE 4. Proportion of vasculitis (\%) by gender and age groups

SLIKA 4. Udio vaskulitisa (\%) prema spolu i dobnim skupinama 
In addition to thrombosis, aCL was elevated in two studies, while elevated aCL without recorded thrombosis was present in a Latin American and another American study $(10,12,14,15)$. In those studies, LAC was elevated, and in one elevated aCL-IgG was found (14). Only one study conducted by British authors found reduced levels of aCL-IgM in men versus women (16). In men with elevated aCL, the triggers for thrombotic events were immobility, smoking, and dyslipidemia (12-16).

Vasculitis as a manifestation of SLE was noted in 17 (6\%) subjects, of whom 5 (19\%) were men and $12(5 \%)$ were women. Our study proved with statistical significance that gender and vasculitis were related in our patients. The proportion of vasculitis was 3.8 times higher in men than in women, and the likelihood of vasculitis in men was 4.5 times higher than in women. In 1987 Sthoeger observed a higher incidence of vasculitis among men (13). In a Mexican study, vasculitis was more prevalent in male patients with SLE; both the disease and follow-up lasted longer, and patients were younger at the time of disease detection.

Clinical manifestations of SLE associated with vasculitis were myocarditis, psychosis, Raynaud phenomenon, serositis, leukopenia, lymphopenia, pleuritic, and APS (17). A Catalan study on vasculitis in SLE found it in $11 \%$ of respondents, but did not provide data on the gender association. One third of the patients in that study had associated autoimmune diseases including APS, SS, autoimmune hepatitis, and SSc, and according to localization, cutaneous vasculitis was the most common. Patients with vasculitis had a higher disease activity and a higher prevalence of lymphopenia and hypocomplementemia. More manifestations associated with APS, such as livedo reticularis and elevated aCL, have been found in patients with SLE and vasculitis versus those without vasculitis (18).

Therefore, the possible role of aCL or APS in the pathogenesis of vasculitis in SLE patients is being onsidered, as some manifestations such as arterial occlusion, venous thrombosis, leg ulcers, livedo reticularis, and thrombocytopenia have been shown to correlate with APS as well as with vasculitis (17: 19-22). Our significant result in favor of men is a possible consequence of the fact that men, according to some studies, have a more severe clinical picture of SLE with higher disease activity than women, and the higher incidence of APS in men certainly contributed to our result (17).

In our study, SS was significantly associated with the female gender. The proportion of SS was 6 times higher and the probability of its occurrence (OR) was 8 times higher in women than in men. According to previous studies in which a difference in the incidence of SS and / or sicca syndrome was observed, there was no significant difference between genders, but in all of them the pojavnost APS-a 3,7 puta veći nego u žena. Ovakvi se rezultati podudaraju s rezultatima nekoliko objavljenih istraživanja. Gotovo u svim istraživanjima, u kojima je dokazana razlika u pojavnosti APS-a između muškaraca i žena oboljelih od SLE-a, u muškaraca je APS bio češći $(10-13)$. Uz trombozu je u dva istraživanja bio povišen i aCL, dok je povišen aCL bez zabilježenih tromboza bio prisutan u latinoameričkom i još jednom američkom istraživanju $(10,12,14,15)$. U tim je istraživanjima najčešće bio povišen LAC, a u jednom aCL-IgG (14). Samo je u jednom istraživanju britanskih autora utvrđena snižena razina aCL-IgM u muškaraca naspram ženama (16). U muškaraca s povišenim aCL-om okidač za nastanak trombotskih događaja bili su nepokretnost, pušenje i dislipidemija $(12-16)$.

Vaskulitis kao manifestacija SLE-a zabilježen je kod 17 (6\%) ispitanika, od kojih su 5 (19\%) bili muškarci, a 12 (5\%) žene. Sa statističkom značajnošću dokazali smo da su u naših pacijenata spol i vaskulitis povezani. Udio vaskulitisa bio je 3,8 puta veći u muškaraca nego u žena, a izgledi za vaskulitis bili su kod muškaraca 4,5 puta veći od onih u žena. Sthoeger je još 1987. uočio veću pojavnost vaskulitisa među muškarcima (13). I u meksičkom je istraživanju vaskulitis bio zastupljeniji kod muškog spola, u bolesnika sa SLE-om i vaskulitisom bolest i vrijeme praćenja dulje su trajali, a bolesnici su bili mlađe dobi pri otkrivanju bolesti. Kliničke manifestacije SLE-a povezane s vaskulitisom bile su miokarditis, psihoza, Raynaudov fenomen, serozitis, leukopenija, limfopenija, pleuritis i APS (17). Katalonsko istraživanje o vaskulitisu u SLE-u otkriva ga u $11 \%$ ispitanika, ali nije dalo podataka o spolnoj povezanosti. Trećina bolesnika u tom istraživanju imala je pridružene autoimunosne bolesti uključujući APS, SS, autoimunosni hepatitis i SSc, a prema lokalizaciji, najčešći je bio kožni vaskulitis. Bolesnici s vaskulitisom imali su veću aktivnost bolesti te veću prevalenciju limfopenije i hipokomplementemije. Više manifestacija koje su povezane s APS-om poput livedo reticularis i povišenog aCL-a nađeno je u bolesnika sa SLE-om i vaskulitisom naspram onima bez vaskulitisa (18). Stoga se i razmatra moguća uloga aCL-a ili APS-a u patogenezi vaskulitisa u oboljelih od SLE-a, budući da su neke manifestacije poput arterijske okluzije, venskih tromboza, ulkusa nogu, livedo reticularis i trombocitopenije pokazale korelaciju s APS-om, kao i s vaskulitisom $(17,19-22)$. Naš znatan rezultat u korist muškaraca moguća je posljedica toga što muškarci, prema nekim istraživanjima, imaju težu kliničku sliku SLE-a, $s$ većom aktivnosti bolesti od žena, a svakako tomu pridonosi i veća pojavnost APS-a u muškaraca (23).

U našem je istraživanju SS znatno povezan sa ženskim spolom. Udio SS-a 6 je puta veći, a izgled za njegovu pojavnost (OR) 8 je puta veći u žena nego kod 
incidence of SS was higher in women than in men. Thus in a Greek study $1.7 \%$ of men and $3.37 \%$ of women had SS, while sicca syndrome was present in $5.1 \%$ of men and $11 \%$ of women (2).

In a study conducted by Renau and Isenberg, it was also observed that SS is more common in women (9.9\%) versus men (6.7\%) (16). We explain our result by the fact that SS is generally more common in women, and the ratio of women to men in our study was 10: 1 (25).

According to our research, associated neoplasms showed a significant correlation with the female gender, and they were mostly benign tumors. Gynecological tumors, uterine fibroids, polyps, and ovarian cysts predominated. Dysplasia and cervical cancer are known to be associated with HPV infection, which is more common in individuals with SLE. Other gynecological tumors, such as polyps and uterine fibroids, are associated with female sex hormones, the importance of which has already been mentioned in the introduction. Other benign neoplasms of other sites were cysts (liver, kidney, parotid gland, lung, breast, and spleen), hemangiomas of the liver, brain angiomas, polyps, and adenomas of various sites.

Malignant tumors were present on the thyroid gland in one patient, three had papillary thyroid carcinoma, and one patient had cervical cancer. Other localizations of gynecological malignancies were the vulva, fallopian tube, and uterus. The remaining malignancies were cancer of the lung, kidney, bladder, Bauhinia valve, colon, and skin. The only neoplasm we noted in men was hemangioma of the liver. No significant gender difference in tumors was observed in other studies, but a study by Antonelli et al. showed that there was a higher incidence of papillary thyroid cancer among patients with SLE (26).

Extensive research on comorbidities in SLE suggests an increased overall risk of developing malignancy and an increased incidence among men (27). Bernatsky et al. warned about a slightly increased risk of developing malignancies in SLE, particularly lung cancer, lympho$\mathrm{ma}$, and other hematologic malignancies according to previous studies $(28,29)$.

Neither a higher risk of vulvar, thyroid, and pancreatic malignancies nor a reduced risk of breast or endometrial tumors were confirmed in SLE $(30,31)$. In contrast to our results, Crosslin and Wiginton found more malignancies in men than in women (23). It has been hypothesized that the increased risk of malignancy in patients with SLE is due to a damaged immune system, immunosuppressive drugs, and elevated common risk factors such as smoking (31).

A total of $64(24 \%)$ patients in our study had lupus nephritis, of which $8(31 \%)$ were men and $56(23 \%)$ were women. Although we did not get a statistically muškaraca. Prema dosadašnjim istraživanjima, u kojima je promatrana razlika u pojavnosti SS-a i/ili sindroma sicca, nije bilo znatne razlike među spolovima, no u svima je pojavnost SS-a bila veća u žena nego kod muškaraca. Tako je u grčkom istraživanju SS imalo $1,7 \%$ muškaraca i $3,37 \%$ žena, dok je sindrom sicca bio prisutan u 5,1\% muškaraca, a $11 \%$ žena (24). U istraživanju Renaua i Isenberga također je primijećeno da je SS češći u žena $(9,9 \%)$ naspram muškarcima $(6,7 \%)$ (16). Naš rezultat objašnjavamo činjenicom da je SS inače učestaliji kod žena, a omjer žena i muškaraca bio je $10: 1(25)$.

Pridružene neoplazme pokazale su, prema našem istraživanju, znatnu povezanost sa ženskim spolom, a uglavnom se radilo o benignim tumorima. Prednjačili su ginekološki tumori, miomi maternice, polipi i ciste jajnika. Poznato je da su displazije i rak grla maternice povezani s infekcijom HPV-om koja je učestalija kod oboljelih od SLE-a. Ostali ginekološki tumori kao, npr., polip i miom maternice povezani su sa ženskim spolnim hormonima, o čijoj smo važnosti u SLE-u već pisali u uvodu. Od ostalih benignih neoplazma drugih sijela bilo je cista (jetre, bubrega, parotidne žlijezde, pluća, dojke i slezene), hemangioma jetre, angioma mozga, polipa i adenoma raznih sijela. Maligni tumori bili su prisutni kod jednog bolesnika na doštitnoj žlijezdi, troje je imalo papilarni karcinom štitnjače, a jedna bolesnica rak vrata maternice. Ostale lokalizacije ginekoloških malignoma bile su vulva, jajovod i maternica. Preostali malignomi bili su karcinomi pluća, bubrega, mokraćnog mjehura, Bauhinijeve valvule, debelog crijeva i kože. Jedina neoplazma koju smo imali zabilježenu kod muškarca bio je hemangiom jetre. U drugim istraživanjima nije zabilježena znatna spolna razlika u tumorima, ali je istraživanje Antonellija i suradnika dokazalo da je među oboljelima od SLE-a veća incidencija papilarnog karcinoma štitnjače (26). Veliko istraživanje komorbiditeta u SLE-u upućuje na povišen ukupni rizik od razvoja malignoma i povećanu pojavnost među muškarcima (27). Bernatsky i suradnici upozorili su na malo povišen rizik od razvoja malignoma u SLE-u, osobito karcinoma pluća, limfoma i drugih hematoloških malignoma sukladno prijašnjim istraživanjima $(28,29)$. U SLE-u nije potvrđen viši rizik od malignoma vulve, štitnjače i gušterače ni snižen rizik od tumora dojke ili endometrija (30, 31). Nasuprot našim rezultatima, Crosslin i Wiginton $\mathrm{u}$ svojem su istraživanju utvrdile više maligniteta u muškaraca nego u žena (23). Pretpostavka je da je povišen rizik od malignoma u bolesnika sa SLE-om posljedica oštećenog imunosnog sustava, imunosupresivnih lijekova i povišenih uobičajenih rizičnih faktora poput pušenja (31).

Lupus nefritis imalo je ukupno 64 (24\%) oboljelih, od čega je bilo 8 (31\%) muškaraca, a 56 (23\%) žena. 
significant result considering the proportion of male and female patients, we found that lupus nephritis is more common in men. Other studies have also confirmed a higher incidence of lupus nephritis in men $(16,23,24)$.

The proportion of lupus nephritis was almost twice as high in the group of patients $<50$ years of age in comparison to the patients aged 50 to 70 years, which is consistent with the results of other studies $(16,24)$.

Skin changes were found in $112(42 \%)$ of our patients with SLE, of which 14 (54\%) were men and 98 (40\%) were women. Most studies analyzed individual skin changes taking gender into consideration; thus, in a study by Tan et al., men were less likely to develop butterfly rash, photosensitivity, oral ulceration, alopecia, and Raynaud phenomenon than women (10). According to a large Latin American cohort of patients with SLE, in men there were fewer cases of alopecia, photosensitivity, butterfly rash, and Raynaud phenomenon (14).

An Asian study also found that alopecia and Raynaud phenomenon were more common in women. Also, in a Greek study photosensitivity, Raynaud phenomenon, and oral ulcerations were more common in women $(32,33)$. We did not get a difference in the incidence of skin changes with respect to gender, as only individual skin changes differed.

Osteoporosis was present in $42(16 \%)$ of our patients, of which only 1 (4\%) was a man and $41(17 \%)$ were women. The proportion of osteoporosis was 5.5 times higher in the group of patients aged 50 to 70 years compared to patients aged $<50$ years, and the probability of osteoporosis in the group of patients aged $50-70$ years was 6.2 times higher than in the group of patients aged $<50$ years. Although the gender gap did not reach the level of statistical significance, our results show that osteoporosis is more common in women than in men with SLE. A Spanish study in the RELESSER cohort showed that osteoporosis with fractures was more common in women, but the difference did not reach statistical significance, similar to our study (12).

Rees et al. found a higher incidence of osteoporosis in women with SLE compared to the control group, while men had a very high relative risk of developing osteoporosis compared with the control group (27). Other factors that can affect the incidence of osteoporosis in men are glucocorticoid use and SLE activity. Salman-Monte et al. reported an incidence of osteoporosis in $8.9 \%$ female patients with SLE and $4.4 \%$ of consequent fractures. In each of these women osteopenia was diagnosed by densitometry, but found no association between bone density and glucocorticoids or disease activity (11).
Iako nismo dobili statistički značajan rezultat $\mathrm{s}$ obzirom na udio muških i ženskih bolesnika, vidimo da je lupus nefritis češći kod muškaraca. I druga su istraživanja potvrdila veću pojavnost lupusnog nefritisa kod muškaraca $(16,23,24)$.

Udio lupusnog nefritisa gotovo je dvostruko veći u skupini bolesnika u dobi $<50$ godina od onoga kod bolesnika u dobi od 50 do 70 godina, što je u skladu s rezultatima drugih istraživanja $(16,24)$.

Kožne promjene imalo je 112 (42\%) naših bolesnika sa SLE-om, od kojih je bilo 14 (54\%) muškaraca, a 98 (40\%) žena. Većina istraživanja analizirala je pojedinačne kožne promjene s obzirom na spol pa su u istraživanju Tana i suradnika muškarci imali manji izgled da se u njih razviju leptirasti osip, fotosenzitivnost, oralne ulceracije, alopecija i Raynaudov fenomen nego žene (10). Prema velikoj latinoameričkoj kohorti bolesnika sa SLE-om, u muškaraca je bilo manje alopecije, fotosenzitivnosti, leptirastog osipa i Raynaudova fenomena (14). Azijsko je istraživanje također pokazalo da su alopecija i Raynaudov fenomen češći u žena, a u grčkom su istraživanju fotosenzitivnost, Raynaudov fenomen i oralne ulceracije bili učestaliji kod žena (32, 33). Nismo dobili razliku u pojavnosti kožnih promjena s obzirom na spol, jer se razlikuju samo pojedinačne kožne promjene.

Osteoporozu su imala $42(16 \%)$ naša bolesnika, od kojih je u skupini muškaraca bio samo 1 (4\%), a žena je bila 41 (17\%). Udio osteoporoze bio je 5,5 puta veći u skupini bolesnika u dobi od 50 do 70 godina u odnosu prema bolesnicima u dobi $<50$ godina, a izgled za pojavnost osteoporoze u skupini bolesnika u dobi od 50 - 70 godina bio je 6,2 puta veći nego u skupini bolesnika u dobi $<50$ godina. Premda razlika među spolovima nije dosegla razinu statističke značajnosti, naši rezultati pokazuju da je osteoporoza češća u žena nego u muškaraca oboljelih od SLE-a. Španjolsko istraživanje na kohorti RELESSER pokazalo je da je osteoporoza s frakturama češća kod žena, ali razlika nije dosegla statističku značajnost slično kao i u našem istraživanju (12). Rees i suradnici utvrdili su veću pojavnost osteoporoze u žena oboljelih od SLE-a u odnosu prema kontrolnoj skupini, dok su muškarci imali vrlo visok relativni rizik od razvoja osteoporoze u usporedbi s kontrolnom skupinom (27). Ostali faktori koji mogu utjecati na pojavnost osteoporoze i kod muškaraca jesu upotreba glukokortikoida i aktivnost SLE-a. Salman-Monte i suradnici izvijestili su o učestalosti osteoporoze od $8,9 \%$ u bolesnica sa SLE-om i 4,4\% posljedičnih prijeloma. Svakoj od tih žena denzitometrijom je dokazana osteopenija, no nisu našli povezanost između gustoće kostiju i glukokortikoida ili aktivnosti bolesti (11).

Prema istraživanju Reesa i suradnika, incidencija kardiovaskularnih bolesti (KVB), malignoma i osteo- 
According to the research by Rees et al., the incidence of cardiovascular disease (CVD), malignancy, and osteoporosis in SLE increased with age; the incidence of infections did not show an age association, while the incidence of end-stage renal failure decreased with age. The risk of all comorbidities, except infection, was elevated at a younger age compared to the controls (27).

Our results greatly coincide with the results of Rees et al., although we had a different division of age groups. Since we considered heart disorders as all disorders of the endocardium, myocardium, pericardium, as well as coronary blood vessels, we cannot compare this variable with the CVD variable from that study.

Hypertension and dyslipidemia are traditional risk factors for CVD and, like CVD in our study, are more common in elderly patients. Still, the question remains as to how much of this is a consequence of age and how much of SLE activity, but given the absence of a control group without SLE, we could not examine it.

There were several other limitations to our study. First and foremost is the large difference in the representation of men and women, which is a reflection of the real difference in the incidence of this disease. Another limitation is the retrospective data and part of the comorbidities that were suspected, but without clear evidence. A number of patients did not come for regular follow-up, so it is possible that some clinical manifestations or comorbidities were missed.

In conclusion, differences in clinical manifestations and comorbidities between women and men with SLE were found in a sample of our population. The incidence of SS and associated neoplasms is much higher in women than in men, while in men with SLE, the incidence of APS and vasculitis is higher than in women. Hypertension and dyslipidemia are more common in women than in men in the population of our patients with SLE. Lupus nephritis and skin changes occur in both genders in younger patients. In order to elucidate this problem more clearly, it is necessary to examine a much larger population of patients and monitor them for a longer period of time.

Conflict of interest statement: Authors declare no conflict of interest. poroze u SLE-u rasla je s dobi; incidencija infekcija nije pokazivala dobnu povezanost, dok se incidencija terminalnog stadija zatajenja bubrega s godinama smanjivala. Rizik od svih komorbiditeta, osim infekcije, u mlađoj je dobi bio povišen u usporedbi s kontrolom (27). Naši se rezultati uvelike podudaraju s rezultatima Reesa i suradnika, premda smo imali drugačiju podjelu dobnih skupina. S obzirom na to da smo pod zahvaćenošću srca razumijevali sve poremećaje endokarda, miokarda, perikarda, kao i koronarnih krvnih žila, tu varijablu ne možemo uspoređivati s varijablom KVB-a iz ovog istraživanja.

Hipertenzija i dislipidemija tradicionalni su rizični čimbenici za KVB te su, kao i KVB u ovom istraživanju, češći kod starijih bolesnika. Ipak, ostaje otvoreno pitanje koliko je to posljedica dobi, a u kojoj mjeri aktivnosti SLE-a, ali s obzirom na nepostojanje kontrolne skupine bez SLE-a, nismo to ni mogli istražiti.

U našem je istraživanju bilo još nekoliko ograničenja. Prvo i najvažnije jest velika razlika u zastupljenosti muškaraca i žena koja je odraz stvarne razlike u pojavnosti ove bolesti. Druga su slabost retrospektivno uzimani podatci i dio komorbiditeta na koje se sumnjalo, ali bez jasnog dokaza. Dio bolesnika nije dolazio na redovite kontrole pa je moguće da su neke kliničke manifestacije ili komorbiditeti promakli evidentiranju.

Zaključno, u uzorku naše populacije nađene su razlike u kliničkim manifestacijama i komorbiditetima između žena i muškaraca oboljelih od SLE-a. Izgled za pojavnost SS-a i pridruženih neoplazma višestruko je veći u žena nego u muškaraca, dok je kod muškaraca sa SLE-om veći izgled za pojavnost APS-a i vaskulitisa nego u žena. Hipertenzija i dislipidemija češće su u žena nego u muškaraca u populaciji naših bolesnika sa SLE-om. Lupus nefritis i kožne promjene javljaju se kod oba spola u bolesnika mlađe dobi. Radi jasnijeg objašnjenja ovog problema potrebno je istražiti puno veću populaciju bolesnika te ih pratiti dulje razdoblje.

Izjava o sukobu interesa: Autori izjavljuju da nisu u sukobu interesa.

Translated on English/Prijevod na engleski Petra Kovačević 


\section{REFERENCES / LITERATURA}

1. Lahita RG. The Clinical Presentations of Systemic Lupus Eritematosus. U: Lahita RG, Tsokos G, Buyon JP, Koike T (ur.). Systemic Lupus Erythematos. Academic Press; 2010., str. 525-41.

2. Jönsen A, Clarke AE, Joseph L, Belisle P, Bernatsky S, Nived OA i sur. Association of the Charlson Comorbidity Index with Mortality in Systemic Lupus Erythematosus. Arthritis Care Res (Hoboken). 2011;63:1233-7.

3. Pons-Estel GJ, Ugarte-Gil MF, Alarcón GS. Epidemiology of systemic lupus erythematosus. Expert Rev Clin Immunol. 2017;13:799-814.

4. González LA, Alarcón GS. The evolving concept of SLE comorbidities. Expert Rev Clin Immunol. 2017;13:753-68.

5. Urowitz MB, Gladman D, Ibañez D, Bae SC, Sanchez-Guerrero J, Gordon C i sur. Atherosclerotic vascular events in a multinational inception cohort of systemic lupus erythematosus. Arthritis Care Res (Hoboken). 2010;62:881-7.

6. Choi MY, Flood K, Bernatsky S, Ramsey-Goldman R, Clarke AE. A review on SLE and malignancy. Best Pract Res Clin Rheumatol. 2017;31:373-96.

7. Setoue DN, Pitta AC, Fiorot FJ, Nastri MM, Novak GV, Molinari BC i sur. Symptomatic polyautoimmunity at diagnosis of 1463 childhood-onset lupus. Autoimmun Rev. 2018;17(8): 836-9.

8. Ruiz-Irastorza G, Olivares N, Ruiz-Arruza I, Martinez-Berriotxoa A, Egurbide MV, Aguirre C. Predictors of major infections in systemic lupus erythematosus. Arthritis Res Ther. 2009;11:R109.

9. Boodhoo KD, Liu S, Zuo X. Impact of sex disparities on the clinical manifestations in patients with systemic lupus erythematosus: a systematic review and meta-analysis. Medicine (Baltimore). 2016;95:e4272.

10. Tan TC, Fang H, Magder L, Petri MA. Differences between male and female systemic lupus erythematosus in a multiethnic population. J Rheumatol. 2012;39:759-69.

11. Stefanidou S, Benos A, Galanopoulou V. Clinical expression and morbidity of systemic lupus erythematosus during a postdiagnostic 5-year follow-up: a male:female comparison. Lupus. 2011;20:1090-4.

12. Riveros Frutos A, Casas I, Rúa-Figueroa I, López-Longo FJ, Calvo-Alén J, Galindo M i sur. Systemic lupus erythematosus in Spanish males: a study of the Spanish Rheumatology Society Lupus Registry (RELESSER) cohort. Lupus. 2017;26:698-706.

13. Sthoeger ZM, Geltner D, Rider A, Bentwich Z. Systemic lupus erythematosus in 49 Israeli males: a retrospective study. Clin Exp Rheumatol. 1987;5:233-40.

14. Garcia MA, Marcos JC, Marcos AI, Pons-Estel BA, Wojdyla D, Arturi A. Male systemic lupus erythematosus in a Latin-American inception cohort of 1214 patients. Lupus. 2005;14:938-46.

15. Rivest C, Lew RA, Welsing PM, Sangha O, Wright EA, Roberts WN i sur. Association between clinical factors, socioeconomic status, and organ damage in recent onset systemic lupus erythematosus. J Rheumatol. 2000;27:680-4.

16. Renau AI, Isenberg DA. Male versus female lupus: a comparison of ethnicity, clinical features, serology and outcome over a 30 year period. Lupus. 2012;21:1041-8.
17. Drenkard AR, Villa E, Reyes M, Abello D, Allarcón-Segovia A. Vasculitis in systemic lupus erythematosus. Lupus. 1997:6; 235-42.

18. Ramos-Casals M, Nardi N, Lagrutta M, Brito-Zerón P, Bové A, Delgado G. Vasculitis in systemic lupus erythematosus: Prevalence and Clinical Characteristics in 670 patients. Medicine. 2006;85:95-104.

19. Alarcón-Segovia D, Pérez-Vázquez ME, Villa AR, Drenkard C, Cabiedes J. Preliminary classification criteria for the antiphospholipid syndrome within systemic lupus erythematosus. Semin Arthritis Rheum. 1992;21:275-86.

20. Danning CL, Illei GG, Boumpas DT. Vasculitis associated with primary rheumatologic diseases. Curr Opin Rheumatol. 1998; 10:58-65.

21. Goldberger E, Elder RC, Schwartz RA, Phillips PE. Vasculitis in the antiphospholipid syndrome. A cause of ischemia responding to corticosteroids. Arthritis Rheum. 1992;35:569-72.

22. Toussirot E, Figarella-Branger D, Disdier P, Harle JR, Weiller PJ. Association of cerebral vasculitis with a lupus anticoagulant. A case with brain pathology. Clin Rheumatol. 1994;13: 624-7.

23. Crosslin KL, Wiginton KL. Sex differences in disease severity among patients with systemic lupus erythematosus. Gend Med. 2011;8:365-71.

24. Voulgari PV, Katsimbri P, Alamanos Y, Drosos AA. Gender and age differences in systemic lupus erythematosus. A study of 489 Greek patients with a review of the literature. Lupus. 2002; 11:722-9.

25. Brito-Zerón P, Baldini C, Bootsma H, Bowman SJ, Jonsson R, Mariette X i sur. Sjögren syndrome. Nat Rev Dis Primers. 2016; 2:16047.

26. Antonelli A, Mosca M, Fallahi P, Neri R, Ferrari SM, D’Ascanio A i sur. Thyroid cancer in systemic lupus erythematosus: a case-control study. J Clin Endocrinol Metab. 2010;95:314-8.

27. Rees F, Doherty M, Grainge M, Lanyon P, Davenport G, Zhang W. Burden of Comorbidity in Systemic Lupus Erythematosus in the UK, 1999-2012. Arthritis Care Res (Hoboken). 2016; 68(6):819-27.

28. Bernatsky S, Ramsey-Goldman R, Labrecque J, Joseph L, Boivin JF, Petri M i sur. Cancer risk in systemic lupus: an updated international multi-centre cohort study. J Autoimmun. 2013;42:130-5.

29. Sultan SM, Ioannou Y, Isenberg DA. Is there an association of malignancy with systemic lupus erythematosus? An analysis of 276 patients under long-term review. Rheumatology (Oxford). 2000;39:1147-52.

30. Dey D, Kenu E, Isenberg DA. Cancer complicating systemic lupus erythematosus: a dichotomy emerging from a nested case-control study. Lupus. 2013;22:919-27.

31. Gayed M, Bernatsky S, Ramsey-Goldman R, Clarke A, Gordon C. Lupus and cancer. Lupus. 2009;18:479-85.

32. Mongkoltanatus J, Wangkaew S, Kasitanon N. Clinical features of Thai male lupus: an age matched controlled study. Rheumatol Int. 2008;28:339-44.

33. Bono L, Cameron JS, Hicks JA. The very long-term prognosis and complications of lupus nephritis and its treatment. QJM. 1999;92:211-8. 